\title{
Emergent faithfulness to morphological and semantic heads in lexical blends*
}

\author{
Katherine Shaw, Andrew White, Elliott Moreton, and Fabian Monrose \\ University of North Carolina, Chapel Hill
}

\section{Introduction}

1.1 Positional Faithfulness In many languages, sounds in certain positions resist tampering which affects sounds elsewhere (Beckman, 1998). For example, Emai (Benue-Congo; Nigeria) does not allow sequences of two adjacent vowels (Casali, 1996:pp. 51ff.). When a word that begins with a vowel is placed after one that ends in a vowel, something has to change, as shown in (1).

(a) If $V_{1}$ is high and both morphemes are lexical, then $V_{1}$ becomes a glide:

$$
\begin{array}{lll}
/ \mathrm{ku} \text { ame/ } & {[\mathrm{kwam \varepsilon}]} & \text { 'throw (lex.) water (lex.)' } \\
\text { /fi opia/ } & \text { [fjopia] } & \text { 'throw (lex.) cutlass (lex.)' }
\end{array}
$$

(b) else if one morpheme is lexical and one is functional, the vowel in the functional morpheme is deleted:

$$
\begin{array}{lll}
\text { /oli ebe/ } & \text { [olebe] } & \text { 'the (func.) book (lex.)' } \\
\text { /ukpode ona/ } & \text { [ukpodena] } & \text { 'road (lex.) this (func.)' }
\end{array}
$$

(c) In all other cases, $V_{1}$ is deleted:

$$
\begin{array}{lll}
/ \text { ko ema/ } & \text { [kema }] & \text { 'plant (lex.) yam (lex.)' } \\
/ \text { fa edi/ } & {[\text { fedi }]} & \text { 'pluck (lex.) palm-nut (lex.)' }
\end{array}
$$

Lexical morphemes in Emai are a "privileged position" compared to functional ones: The vowel in the function morpheme is tampered with to spare the vowel in the lexical morpheme.

Previous research has identified phonological privilege in several other positions, including word-initial syllables (Beckman, 1998), stressed syllables (Alderete, 1995), syllable onsets (Lombardi, 1999), nouns (Smith, 2001), proper nouns (Jaber, 2011), and morphological roots (Alderete, 1999). The Positional Faithfulness hypothesis is that these effects are caused by position-specific versions of ordinary, general faithfulness constraints. For example, Revithiadou proposes that underlying stress and accent are protected by positional privilege in morphological heads (taking the head to be the element that determines the lexical category, gender, and other morphosyntactic properties) (Revithiadou, 1999). The phenomenon is illustrated in (2).

Head faithfulness to stress in Russian compound formation (Roon, 2006):

(a) kinó 'film' + zvezdá 'star' $\Rightarrow$ kinozvezdá 'movie star'

(b) betón 'concrete' + mefálka 'mixer' $\Rightarrow$ betonomefálka 'concrete mixer'

In these examples, as in Russian subordinating compounds generally, the compound preserves the stress of only one of its constituents, the head. To model the phenomenon, Roon (2006) proposes an Output-Output

\footnotetext{
* The authors are indebted to Katya Pertsova, Jen Smith, Matt Fuller, Roger Que, Rachel Broad, Greg Stephen, as well as audiences at UNC's P-Side Caucus, departmental colloquium, and Phonology 2013 at UMass-Amherst. We are grateful to Josiah McCoy for assistance in coding our blend corpus. Any remaining errors are the exclusive responsibility of the authors. Work supported in part by NSF Grants CCF 1017318 (Fabian Monrose, PI) and CNS 1318520 (Fabian Monrose, PI; Jen Smith and Elliott Moreton, co-PIs).
} 
Faithfulness constraint (Benua, 1997) that specifically protects the head's stress while leaving the non-head stress unprotected. However, since compounds in Russian are right-headed, there is a confound between headedness and linear order: The evidence in (2) is open to the alternative interpretation that it is not the head, but the rightmost element, whose stress is protected.

This paper presents new evidence for head faithfulness which removes the confound with linear order. We argue further that head faithfulness extends to segments as well as to stress and accent, and extends to heads that are semantically determined as well as those that are determined by morphosyntactic properties.

1.2 Lexical blends The evidence for the head-faith hypothesis comes from corpus and experimental studies of English lexical blending, the process by which, e.g., spoon and fork are combined to make spork. (We are concerned here with intentional blend coinages, not with speech errors, which are known to behave differently; Gries 2012.) Blending forces a choice of what to preserve - for example, should blue + green $\Rightarrow$ bleen or $b$ reen (Arndt-Lappe \& Plag, 2013)? — and so provides an opportunity for positional-faithfulness effects to emerge. We will focus on two types of blend, shown in (3): right-headed, where the first source word modifies the second, and coordinating, where both have equal status. ${ }^{1}$

Semantic relations in blends: the criterion of hyponymy (Bat-El, 2006)

\begin{tabular}{lllll} 
& Word 1 & Word 2 & blend & \\
\hline Right-headed & motor & hotel & motel & a kind of hotel (hyponym) \\
Coordinating & spoon & $\underline{\text { fork }}$ & spork & equally spoon and fork
\end{tabular}

It has previously been found that naturally-occurring Japanese, English, and Spanish blends, the first word typically suffers less deletion, while the second word is more likely to determine the prosody of the blend (Kubozono, 1989, 1990; Gries, 2004b,a; Piñeros, 2004). One response to this observation has been to posit faithfulness constraints distinguishing the Word 1 position from the Word 2 position (Bat-El \& Cohen, 2012). An alternative proposal notes that blends, like compounds, tend to be right-headed, so that Word 2 is usually the syntactic or semantic head of the blend, and hypothesizes faithfulness to the head's prosody and the non-head's segmentism (Piñeros, 2004; Trommer \& Zimmermann, 2010; Ahn, 2013).

Our position differs from both of these. We propose that the head of a blend is a psycholinguistically strong position in the sense of Beckman (1998), and hence that both its prosody and its segmentism are protected by Positional Faithfulness constraints. We therefore hypothesize that blends will be more faithful to Word 2's segments and prosody in blends where Word 2 is the unique head than in blends where Words 1 and 2 have coordinate status.

Our criteria for imputing internal structure to a blend are as follows. If the source words belong to different lexical categories, then the blend is classified as headed ("subordinating"), and the head is taken to be the source word that has the category of the blend. For example, in cabaret $(\mathrm{N})+$ crazy $(\mathrm{A}) \Rightarrow$ cabarazy (A), the head is crazy. But if the source words belong to the same lexical category, then headedness is determined by the criterion of hyponymy (Bat-El, 2006): If $X Y$ is a kind of $Y$, then $X Y$ is subordinating and $Y$ is its head, but if $X Y$ is equally $X$ and $Y$, then it is coordinating, and has no head. Thus, motel (from motor $+\underline{\text { hotel) }}$ is subordinating, with hotel as its head, while spork (equally spoon and fork) is coordinating and headless.

The head-faithfulness hypothesis motivates the otherwise unmotivated proposal that Word 2 is a privileged position. It unifies positional faithfulness in blend formation with positional faithfulness in other processes, and so generates new hypotheses of head faithfulness in non-blending processes, and of other kinds of positional faithfulness in blending.

\section{Main stress location}

Our formal model of stress determination in blends is based on that of Revithiadou (1999). Two constraints are crucial:

1 Left-headed blends do exist, but are rare (only 21 in our corpus) and are not discussed in this abstract. An example is acceleread, from accelerate $+\underline{\text { read. }}$. 
(a) $\operatorname{MAX}(\mathrm{STRESS})$ : Assign a violation for every main stress in the input which lacks a correspondent in the output.

(b) $\operatorname{MAX}\left(\mathrm{STRESS}_{\text {head }}\right.$ : Assign a violation for every main stress in an input head which lacks a correspondent in the output.

In a subordinating blend, the stress of the head will be protected by MAX(STRESS $)_{\text {head }}$, regardless of how it is ranked with respect to MAX(STRESS). In a coordinating blend, there is no head, and so neither source word's stress will be favored by MAX(STRESS) head. This is shown in (5) and (6).

Stress in right-headed subordinating blends is determined by Word 2:

\begin{tabular}{|c|c|c|}
\hline Input: mótor $+\underline{\text { hotél }}_{\text {head }}$ & MAX $(\text { STRESS })_{\text {head }}$ & MAX(STRESS) \\
\hline a. $\Rightarrow$ motél & & $*$ \\
\hline mótel & $* !$ & $*$ \\
\hline
\end{tabular}

Stress in coordinating blends has no head to be faithful to:

\begin{tabular}{|c|c|c|}
\hline Input: pólo + lacrósse & MAX(STRESS $)_{\text {head }}$ & MAX(STRESS $)$ \\
\hline$\Rightarrow$ pólacrosse & & $*$ \\
\hline polacrósse & & $*$ \\
\hline
\end{tabular}

There will of course be many other stress-related constraints (not shown) that do not involve heads. These constraints affect right-headed and coordinating blends alike. However, if MAX(STRESS $)_{\text {head }}$ is ranked high enough, it will enforce more preservation of Word 2 stress in right-headed subordinating blends than in coordinating blends.

2.1 Corpus study 1: Headedness and main stress The corpus was drawn from the English blend dictionary of Thurner (1993). It consisted of all the two-source-word blends, other than brand names, that began the way Word 1 began and ended the way Word 2 ended. ${ }^{2}$ The final corpus contained 1095 blends. Blend pronunciations were taken from dictionaries where possible (Carnegie Mellon Speech Group, 2007; Oxford English Dictionary, 2013; Merriam-Webster Dictionary, 2003); otherwise, they were assigned by two independent native English speakers, one naïve to the purpose of the study. The 38 disagreements between the two speakers were resolved by a panel of 2-4 naïve native English speakers.

Blends were scored as coordinating or right-headed by applying the morphological and hyponymy criteria to Thurner's definition. A blend was scored as preserving stress location of Word 1 (Word 2) if the same number of syllables preceded (followed) main stress in both, as shown in (7) (Shaw, 2013; Arndt-Lappe \& Plag, 2013).

\section{Preservation of stress location relative to source-word edges: examples}

\begin{tabular}{|c|c|c|c|c|}
\hline $\begin{array}{r}\text { Word 1 } \\
\text { Word } 2 \\
\text { Blend }\end{array}$ & $\begin{array}{c}\text { és ca la tor } \\
\text { líft } \\
\text { és ca } \underline{\text { lift }}\end{array}$ & $\begin{array}{l}\text { in de pén dent } \\
\text { Dé mo crat } \\
\text { in } \frac{\text { do }}{\mathrm{crat}}\end{array}$ & $\begin{array}{lll}O & h i ́ & o \\
& \underline{\mathrm{I}} & \underline{\mathrm{o}} \underline{\mathrm{wa}} \\
O & h \underline{i} & \underline{\mathrm{o}} \underline{\mathrm{wa}}\end{array}$ & $\begin{array}{c}\text { (no } \\
\text { examples } \\
\text { in corpus) }\end{array}$ \\
\hline Preserves stress location of Word & 1 & $\underline{2}$ & both & neither \\
\hline
\end{tabular}

The table in (8) shows the results. Among blends that preserved the stress of only one source word, right-headed subordinating blends preserved Word 2 stress significantly more often than did coordinating blends (79\% vs. $66 \% ; \chi^{2}$ on 1 d.f., $\left.p=0.0063\right)$.

Right-headed blends are more faithful to Word 2 stress than are coordinating blends.

\begin{tabular}{lrrr}
\hline & \multicolumn{3}{c}{ Preserves stress location of } \\
\cline { 2 - 4 } Structure & Word 1 & Word 2 & Both \\
\hline Right-headed & 78 & 291 & 338 \\
Coordinating & 44 & 87 & 261 \\
\hline
\end{tabular}

2 This criterion excluded embedded blends like $u$ bookquitous, orthographic blends that sounded identical to a source word like fizzician, "clipped compounds" like situation + comedy $\Rightarrow$ sitcom, blends with three source words like brunner 'all three meals at once', and blends with metathesis like smokolotive. 
2.2 Experiment 1: Headedness and main stress Could the corpus effect be due to some uncontrolled factor, such as the phonological form of the source words? Coiners of naturally occurring blends can choose the source words, and may tend to choose heads and non-heads which differ systematically. For example, English speakers tend to choose source-word pairs in which the second word is longer (Kelly, 1998), which could affect how much head vs. non-head material is preserved in the blend, even in the absence of a headfaith constraint.

This possibility was tested in a web-based experiment in which participants were given a fixed pair of source words and asked to match a pair of blends differing only in stress with a pair of definitions differing in semantic headedness, as shown in (9). Definitions were written to control, as far as possible, other factors such as the order and position of the source words in the definition.

Stress experiment: Which blend goes with which definition?

\begin{tabular}{|ll|}
\hline Stress preserved & Blend \\
\hline Word 1 (flóunder) & flóundine \\
Word 2 (sardíne) & floundíne \\
\hline
\end{tabular}

\begin{tabular}{|ll|}
\hline Structure & Definition \\
\hline Coordinating & A cross between a sardine and a flounder \\
Right-headed & A type of sardine eaten by flounder \\
\hline
\end{tabular}

Our linking hypothesis was that participants would match blends to definitions so as to optimize the two derivations collectively in terms of constraint violations. This is illustrated in (10). Each of the two possible assignments of definitions to blends is a candidate. Both candidates violate MAX(STRESS), but Candidate (b) additionally violates MAX(STRESS) head, and therefore loses to Candidate (a). The two candidates score alike on all constraints not involving headedness and stress, which are therefore not shown.

(10) Predictions for Experiment 1: Right-headed definition should be matched to the blend that is more faithful to Word 2.

\begin{tabular}{|c|c|c|c|c|}
\hline & MAX(STRESS $)_{\text {head }}$ & MAX(STRESS $)$ \\
\hline \multirow[t]{2}{*}{$\Rightarrow \quad \mathrm{a}$} & flóunder+sardíne & $d \rightarrow$ floundíne & & * \\
\hline & flóunder+sardíne & $\rightarrow$ flóundine & & * \\
\hline \multirow[t]{2}{*}{ 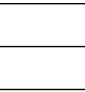 } & flóunder+sardíne & $\rightarrow$ floundíne & & $*$ \\
\hline & flóunder+sardíne & $d \rightarrow$ flóundine & $* !$ & * \\
\hline
\end{tabular}

Each of 8 blend pairs was presented in both audio and writing (marking stress as in (9)) with written definitions to 43 native English speakers. A response was scored as head-faithful if the right-headed subordinating definition was matched to the blend that preserved Word 2 stress. Aggregated across all participants, $67 \%$ of responses were head-faithful. Each participant could give from 0 to 8 head-faithful responses. Actual results are shown in (11). 


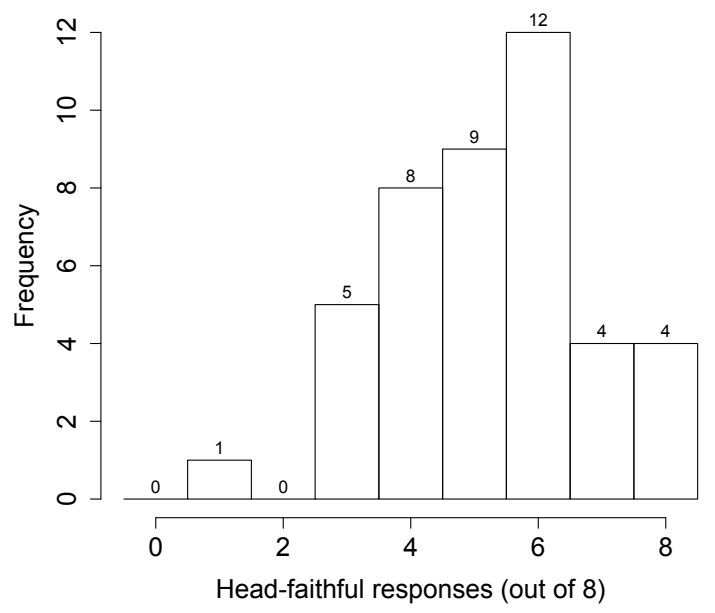

Eight participants scored at chance (4 head-faithful responses and 4 head-unfaithful). Of the 35 participants who were not at chance, 29 gave more head-faithful responses, while 6 gave more head-unfaithful ones. This difference is significant by an exact binomial test (29 successes out of 35, $p=0.0001168$, using binom. test in Version 2.7.1 of R). These results replicate the corpus pattern controlling other variables, and confirm its psychological reality: Semantic headedness affects blend stress.

\section{Segmental content}

An alternative explanation for the experimental stress results is augmentation via Positional Markedness (Zoll, 1998; Smith, 2004). Positional Markedness theory is based on the observation that languages frequently restrict marked structure to prominent positions; e.g., Tuyuca restricts default stress (marked) to morphological roots (prominent) (Smith, 2002:§4.2.2).

The Positional Markedness hypothesis is that markedness constraints can be relativized to prominent positions (Zoll, 1998). This hypothesis could explain the results of Experiment 1 without Positional Faithfulness. Instead of the faithfulness constraint MAX(STRESS) head, the relevant constraint would be a COINCIDE constraint which penalizes marked structures for occurring outside a prominent position. Word stress is a marked structure (many languages lack it entirely; Hyman 2006) and the head is a prominent position, so we may expect the constraint set to include COINCIDE (STRESS, HEAD):

(12) CoINCIDE (STRESS, HEAD): Assign a violation for every main stress that occurs outside the head of a word.

(13) Stress in right-headed subordinating blends is determined by Word 2: Positional Markedness analysis.

\begin{tabular}{|c|c|c|}
\hline Input: mótor $+\underline{\text { hotél }}_{\text {head }}$ & COINCIDE (STRESS, HEAD) & MAX(STRESS $)$ \\
\hline a. $\quad \Rightarrow \quad$ motél & & * \\
\hline mótel & $* !$ & * \\
\hline
\end{tabular}

Experiment 1 therefore does not distinguish between the Positional Faithfulness and Positional Markedness accounts. It is clear that the head is showing typical prominent-position behavior, but whether that is due to position-specific faithfulness or position-specific markedness cannot be determined.

However, there is another way to distinguish them. Positional Faithfulness predicts that heads can be protected against segmental deletion as well, since the existence of $\mathrm{MAX}_{\text {head }}$ can be inferred from the existence of MAX. MAX head might then favor preservation of Word 2 segments more strongly in rightheaded blends than in coordinating blends: 
Katherine Shaw, Andrew White, Elliott Moreton, and Fabian Monrose Head faithfulness in lexical blends

(14) MAX head favors preservation of Word 2 segments in right-headed subordinating blends.

\begin{tabular}{|c|c|}
\hline Input: croissant $+\underline{\text { sandwich }}_{h e a d}$ & MAX $_{\text {head }}$ MAX \\
\hline a. $\Rightarrow$ croissandwich & * \\
\hline croissantwich & $* !$ \\
\hline
\end{tabular}

(15) $\mathrm{MAX}_{\text {head }}$ does not favor preserving either source word's segments in coordinating blends.

\begin{tabular}{|l||c|c|}
\hline Input: croissant $+\underline{\text { sandwich }}_{\text {head }}$ & MAX $_{\text {head }}$ & MAX \\
\hline \hline a. $\Rightarrow$ croissandwich & & $*$ \\
\hline b. $\quad$ croissantwich & $* !$ & $*$ \\
\hline
\end{tabular}

We first present evidence that this prediction of Positional Faithfulness is in fact true in English blends. We will then argue that Positional Markedness cannot account for these facts.

3.1 Corpus study 2: Segmental content The prediction was tested using the same corpus. A blend was scored as more faithful to Word 1 (Word 2) if the proportion of source-word segments that survived into the blend was greater for Word 1 (Word 2) than for Word 2 (Word 1). The raw counts are shown in (16).

Segmental preservation as a function of headedness

\begin{tabular}{lrrr}
\hline & \multicolumn{3}{c}{ Preserves greater proportion of } \\
\cline { 2 - 4 } Structure & Word 1 & Word 2 & Both \\
\hline Right-headed & 313 & 213 & 163 \\
Coordinating & 152 & 183 & 66 \\
\hline
\end{tabular}

They appear to strongly contradict the hypothesis, since they clearly show a higher segmental survival rate for Word 1 than Word 2 in right-headed blends, and for Word 2 than Word 1 in coordinating blends. However, there is a confounding factor: Right-headed blends frequently have a short Word 1 and a long Word 2, and segments from shorter source words are more likely to survive (Kaunisto, 2000; Gries, 2004a,b). To model out the effects introduced by blend coiners' choice of source words, we fit a multiple-regression model which included three independent variables. Right-Headed was true when the blend was right-headed, else false. Length Difference was obtained by subtracting the number of segments in Word 2 from the number of segments in the Word 1 (negative when Word 1 is shorter). Overlap Location measures difference in the location of the overlapping portion of the blend relative to the word boundaries. It is obtained by first identifying the longest common substring of the source words, then subtracting the number of segments in Word 1 that follow that substring from the number of segments in Word 2 that precede it (for more details, see Shaw 2013:§3.2.2). Length Difference, Overlap Location, and their interaction are intended to model out the effects of the absolute number of segments contained in the source words or deleted from them. The dependent variable was 1 if the segments in Word 2 had a higher survival rate than those in Word 1; otherwise, it was 0 .

(17) Multiple logistic regression results for segmental deletion in the Thurner corpus.

$\begin{array}{lrrrrl} & \text { Estimate } & \text { s.e. } & t & p & \\ \text { (Intercept) } & 0.0270664 & 0.0110269 & 2.455 & 0.01426 & * \\ \text { Right-Headed } & 0.0239586 & 0.0137056 & 1.748 & 0.08072 & \text {. } \\ \text { Length Difference } & -0.0431237 & 0.0024131 & -17.871 & <2 \mathrm{e}-16 & * * * \\ \text { Overlap } & 0.0108299 & 0.0024628 & 4.397 & 1.2 \mathrm{e}-05 & * * * \\ \text { Length Diff. × Overlap } & -0.0016973 & 0.0005717 & -2.969 & 0.00305 & * *\end{array}$

The effect of Right-Headed is positive, as predicted (i.e., when the other factors are controlled, rightheaded blends are more likely to have a higher survival rate for Word 2 segments than for Word 1 segments), but the effect is small (0.024 logits) and only marginally significant ( $p=0.08)$. Moreover, even with the additional factors, the model is a poor fit to the corpus data $\left(R^{2}=0.28\right)$, indicating that deletion is affected by many unmodelled factors. Identifying those factors is a matter for further research; it is already clear that they are numerous (Gries, 2012). In the meantime, Experiment 2 was designed to test for head faithfulness in a thoroughly controlled experimental situation. 
3.2 Experiment 2: Segmental content To control factors other than headedness, this experiment exploited ambi-blendable source-word pairs like those shown in (18). The consonants immediately preceding and following the main-stressed vowel were the same in both source words. The blend could switch between source words at either of these two points, yielding two blend candidates - flamongoose and flamingoose which preserve different amounts of the two source words.

Construction of "ambi-blendable" source-word pairs used in Experiment 2.

$\begin{array}{llllllllll}\text { flamingo } & \mathrm{f} & 1 & \text { ə } & \mathrm{m} & \text { Í } & \mathrm{y} & \mathrm{g} & \mathrm{ou} & \\ & & & & \downarrow & & \downarrow & & & \\ \text { mongoose } & & & & \mathrm{m} & \text { á } & \mathrm{g} & \mathrm{g} & \mathrm{u} & \mathrm{s}\end{array}$

The experimental task was to match the blend candidates with right-headed vs. coordinating definitions, as shown in (19).

Segmental experiment: Which blend goes with which definition?

\begin{tabular}{|ll|}
\hline Preserves more of & Blend \\
\hline Word 1 flamingo & flamingoose \\
Word 2 mongoose & flamongoose \\
\hline
\end{tabular}

\begin{tabular}{|ll|}
\hline Structure & Definition \\
\hline Coordinating & A hybrid of a mongoose and a flamingo \\
Right-headed & A mongoose that preys on flamingos \\
\hline
\end{tabular}

As in Experiment 1, the linking hypothesis is that participants match blends to candidates so as to optimize constraint violations. This predicts that Candidate (20b), which violates $\mathrm{MAX}_{\text {head }}$ twice, will lose to Candidate (20a), which does not violate it at all. (Both candidates score alike on constraints which do not involve headedness or segmental preservation, which are therefore not shown.)

(20) Predictions for Experiment 2: Right-headed definition should be matched to the blend that is more faithful to Word 2.

\begin{tabular}{|c|c|c|c|c|c|}
\hline & & & & MAX $_{\text {head }}$ & MAX \\
\hline & \multirow[t]{2}{*}{ a. } & \multicolumn{2}{|c|}{ flamingo+mongoose $\underline{\text { head }} \rightarrow$ flamongoose } & & I $\mathrm{gg} \mathrm{ou}$ \\
\hline & & flamingo+mongoose & $\rightarrow$ flamingoose & & ov $\underline{\mathrm{ma}}$ \\
\hline & b. & flamingo+mongoose & $\rightarrow$ flamongoose & & I $\mathrm{gg} \mathrm{ou}$ \\
\hline & & flamingo+mongoose $h$ & $\rightarrow$ flamingoose & $\underline{\mathrm{ma}}$ & $o \mho \underline{\mathrm{m} \mathrm{a}}$ \\
\hline
\end{tabular}

Each of 8 blend pairs was presented in writing, with written definitions, to 53 native English speakers. Aggregated across participants, the right-headed definition was matched to the blend that preserved more Word 2 segments on $66 \%$ of trials. A histogram of head-faithful responses per participant is shown in (21). Of the 46 participants whose responses were not split evenly, 40 were more likely to choose the head-faithful response. The difference is significant by an exact binomial test (40 successes out of $46, p=3.01 \times 10^{-17}$ ). 


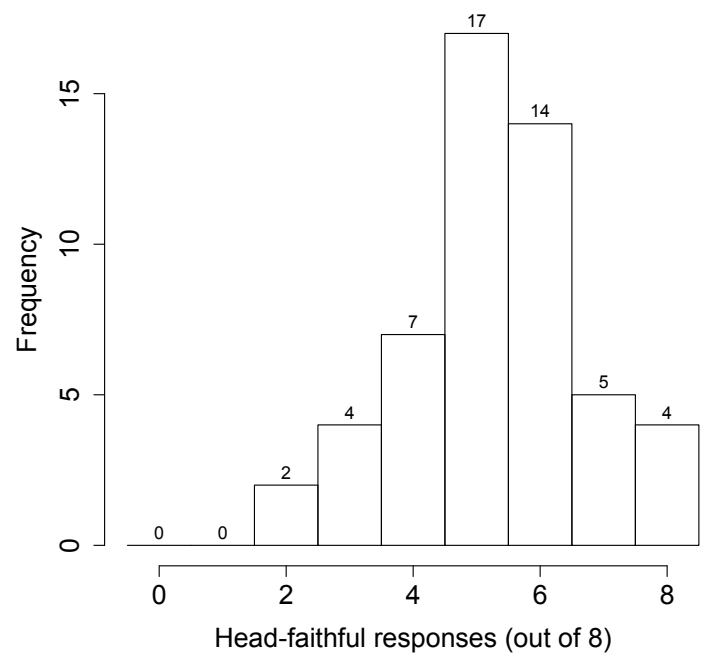

These results support the hypothesis that segments, like stress, are more likely to survive faithfully in a blend when they come from its head than when they do not.

We now return to the question of whether Positional Markedness can provide an alternative explanation for these results. In order to explain why head segments are preserved at the expense of non-head segments, a Zoll (1998)-style Positional Markedness alternative would have to hypothesize a constraint COINCIDE(SEGMENT, HEAD) to favor deleting segments from non-head positions:

(22) Coincide (SEgment, HeAD) (hypothetical): Assign a violation for every segment that occurs outside the head of a word.

To be a valid COINCIDE constraint, COINCIDE(SEGMENT, HEAD) would have to penalize a marked structure in a prominent position. Hence, to propose COINCIDE(SEGMENT, HEAD) is to propose that segments - all segments, just by virtue of being segments - are marked structures. Indeed, (Zoll, 1998) defines COINCIDE $(x, E)$ as a local conjunction of two markedness constraints, one of which is *x. Hence the Positional Markedness alternative implies the existence of a constraint *SEGMENT:

*SEgment (hypothetical): Assign a violation for every segment.

Gouskova (2003) presents several empirical and theoretical arguments against such "nihilistic" constraints, which indiscriminately prohibit all members of a class, even the least marked. For example, if *SEGMENT exists, it has to be stipulated to always be dominated by conflicting constraints in order to avoid the unwelcome typological consequences of allowing it to be undominated by faithfulness. The only available mechanism within Optimality Theory for forcing it to the bottom is a fixed ranking based on a scale of prominence or markedness, but that can only force it below other markedness constraints that lie on the same scale. Since the Positional Markedness alternative leads to pathological predictions, and we know of no other alternative proposals within Optimality Theory or outside it, we conclude that the best available explanation for preferential preservation of head stress and head segmentism in blend outputs is Positional Faithfulness.

\section{Discussion}

The main finding of this study is that English intentional blends tend to preserve the prosody and segmentism of the second source words more strongly when they are semantically right-headed than when they are semantically coordinating. This is true in both a naturally-occurring corpus and in controlled experiments using source-word pairs which can be blended in two different ways. These results are consistent 
with the hypothesis that the semantic head of a blend is a psycholinguistically strong position in the sense of Beckman (1998), and hence is protected by Positional Faithfulness constraints. This hypothesis unifies English blend formation with processes found in the ordinary phonology of other languages, and leads to the prediction that other Positional Faithfulness effects may emerge in blend formation as well. These results have implications for both the study of blends in particular, and for the wider world of phonology in general.

4.1 Head faithfulness and blend phonology We turn now to alternative theoretical proposals relating to the effects of headedness in blend formation. One is that semantic headedness is irrelevant to blend formation (Bat-El, 1996). This proposal is based on the failure of Hebrew blends to exhibit the same head-based phenomena as compounds (with respect to combinatorial possibilities of the source words, and affixation of the output), and on the existence of many semantically headless blends in both Hebrew and English. This proposal is clearly contradicted by the finding that English phonology, and English speakers, treat right-headed blends differently from headless ones.

A second alternative proposal is that blend formation is subject to faithfulness constraints that are specific to the positions "first source word of a blend" and "second source word of a blend" (Bat-El \& Cohen, 2012). These positions are not independently motivated and do not relate blend formation to other phenomena. Moreover, Word 2 faithfulness does not explain why participants in Experiments 1 and 2 preferred to match right-headed definitions with blends that preserved more of Word 2, and coordinating definitions with blends that preserved more of Word 1, as shown in (24).

Word-2 faithfulness predicts no effect in Experiment 1. Compare (10).

\begin{tabular}{|c|c|c|c|}
\hline & & $\operatorname{MAX}(\text { STRESS })_{W o r d 2}$ & MAX(STRESS) \\
\hline \multicolumn{2}{|c|}{$\Rightarrow$ a. flóunder + sardíne $_{W \text { ord } 2} \rightarrow$ floundíne } & & * \\
\hline \multicolumn{2}{|c|}{ flóunder $+\underline{\text { sardíne }}_{W \text { ord } 2} \rightarrow$ flóundine } & $* !$ & * \\
\hline \multirow[t]{2}{*}{$\Rightarrow \quad \mathrm{b}$} & flóunder $+\underline{\text { sardíne }}_{W \text { or } d 2} \rightarrow$ floundíne & & * \\
\hline & flóunder+sardíne ${ }_{W \text { ord } 2} \rightarrow$ flóundine & $* !$ & * \\
\hline
\end{tabular}

A third alternative proposal, much closer in spirit to ours, posits that blends can have heads, and that attributes of the head source word can be treated differently from attributes of the non-head. However, instead of identifying the head as a psycholinguistically strong position (alongside roots, initial syllables, etc.), protected by all the apparatus of Positional Faithfulness, this proposal hypothesizes blend-specific faithfulness to the head's prosody and to the non-head's segmentism (Piñeros, 2004; Trommer \& Zimmermann, 2010). Faithfulness to head prosody is, as we have seen, supported by evidence from Corpus Study 1 and Experiment 1, as well as by corpus studies showing that in Spanish, English, Japanese, Hebrew, and Korean - languages in which blends tend to be right-headed — a blend is more likely to match the second source word than the first in terms of prosodic properties such as syllable or mora count (Kubozono, 1989, 1990; Piñeros, 2004; Bat-El \& Cohen, 2012; Arndt-Lappe \& Plag, 2013; Ahn, 2013).

The position "non-head of a blend", like "Word 1 of a blend", is not independently motivated, and so it would be surprising if there were segmental faithfulness to non-head segments. The results of Corpus Study 2 and, especially, of Experiment 2 are not explained by the hypothesis of faithfulness to non-head segments. Moreover, corpus studies of English blend formation have found that when source-word length differences are controlled, a larger proportion of Word 2's segments survive into the blend than of Word 1's (Kaunisto 2000 not seen; Gries 2004c,b). Since English blends tend to be right-headed, this result is inconsistent with segmental faithfulness to non-heads, but consistent with Positional Faithfulness to heads. The finding of Piñeros (2004), that a subgroup of Spanish blends preferentially preserves prosody from the head but segments from the non-head, may instead be due to the fact that the non-heads are shorter than the heads, combined with the independent tendency for segments to survive better in shorter source words (perhaps in order to facilitate source-word recovery: Kaunisto 2000 not seen; Gries 2004c,b).

4.2 Wider implications Head faithfulness (to segments or to prosody) is not otherwise known to play a role in English phonology. In fact, the main word stress in English compounds usually follows that of the non-head element, as in bútterbean (e.g. Plag, 2006). The emergence of head faithfulness effects in English is therefore evidence for their universality, and so supports the theory of Positional Faithfulness 
(Beckman, 1998) with converging evidence. Thus, it adds to the body of cases in which a process which is general in the phonology of one language emerges unexpectedly in another language in a restricted domain, or under abnormal circumstances ("emergence of the unmarked", or "covert rankings"; e.g., Prince \& Smolensky 1993; McCarthy \& Prince 1995; Broselow 2004; Davidson et al. 2004; Moreton et al. 2008; Berent et al. 2008). These cases are significant because they provide evidence for the universality of grammatical constraints.

Blends, in the wild or in the lab, may thus provide a tool for studying Positional Faithfulness effects. The Positional Faithfulness hypothesis predicts the emergence of other Positional Faithfulness effects in blend formation conditioned by morphological, syntactic, or semantic properties of the source words, such as faithfulness to nouns over verbs (Smith, 2001, 2011), to proper nouns over common ones (Jaber, 2011), or to roots over affixes (Alderete, 1999).

\section{Appendix A: Materials for Experiment 1}

\begin{tabular}{|ll|ll|}
\hline Stress preserved & Blend & Structure & Definition \\
\hline Word 1 (flóunder) & flóundine & Right-headed & A type of sardine eaten by flounder \\
Word 2 (sardíne) & floundíne & Coordinating & A cross between a sardine and a flounder \\
\hline Word 1 (zébra) & zébraffe & Right-headed & A type of giraffe with zebra stripes \\
Word 2 (giráffe) & zebráffe & Coordinating & A cross between a giraffe and a zebra \\
\hline Word 1 (róbin) & róboon & Right-headed & A baboon with a robin-red chest \\
Word 2 (babóon) & robóon & Coordinating & A cross between a baboon and a robin \\
\hline Word 1 (túrkey) & túrcoon & Right-headed & A raccoon that steals turkey eggs \\
Word 2 (raccóon) & turcóon & Coordinating & A cross between a raccoon and a turkey \\
\hline Word 1 (báchelor) & báchelet & Right-headed & A valet who works for a bachelor \\
Word 2 (valét) & bachelét & Coordinating & A valet who is a bachelor \\
\hline Word 1 (bístro) & bístrage & Right-headed & The delivery garage of a bistro \\
Word 2 (garáge) & bist $\underline{\text { ráge }}$ & Coordinating & A building containing both a garage and a bistro \\
\hline Word 1 (pýgmy) & pýg $\underline{\text { mier }}$ & Right-headed & A leader of the pygmies \\
Word 2 (premíer) & pyg $\underline{\text { míer }}$ & Coordinating & A leader who is a pygmy \\
\hline Word 1 (ráisin) & ráissert & Right-headed & A raisin-filled dessert \\
Word 2 (dessért) & raissért & Coordinating & A type of raisin eaten for dessert \\
\hline
\end{tabular}




\section{Appendix B: Materials for Experiment 2}

\begin{tabular}{|c|c|c|c|}
\hline Preserves more of & Blend & Structure & Definition \\
\hline Word 1 (flamingo) & flamingoose & Right-headed & A mongoose that preys on flamingos \\
\hline Word 2 (mongoose) & flamongoose & Coordinating & $\begin{array}{l}\text { A cross between a mongoose and a } \\
\text { flamingo }\end{array}$ \\
\hline Word 1 (baboon) & baboondit & Right-headed & A baboon-stealing bandint \\
\hline Word 2 (bandit) & babandit & Coordinating & A baboon who steals like a bandit \\
\hline Word 1 (buccaneer) & buccaneerrator & Right-headed & Someone who tells pirate stories \\
\hline Word 2 (narrator) & buccanarrator & Coordinating & A pirate who tells stories \\
\hline Word 1 (lampoon) & lampoonishment & Right-headed & $\begin{array}{l}\text { Punishing someone for printing a } \\
\text { lampoon }\end{array}$ \\
\hline Word 2 (punishment) & lampunishment & Coordinating & $\begin{array}{l}\text { Punishing someone by printing lam- } \\
\text { poon }\end{array}$ \\
\hline Word 1 (boutique) & boutixi & Right-headed & A taxi to the local boutiques \\
\hline Word 2 (taxi) & boutaxi & Coordinating & $\begin{array}{l}\text { A taxi with on-board boutique shop- } \\
\text { ping }\end{array}$ \\
\hline Word 1 (impala) & impalcat & Right-headed & A polecat that hunts impalas \\
\hline Word 2 (polecat) & impolcat & Coordinating & A hybrid of a polecat and an impala \\
\hline Word 1 (armadillo) & armadi/phin & Right-headed & $\begin{array}{l}\text { A dolphin with an armadillo's leath- } \\
\text { ery skin }\end{array}$ \\
\hline Word 2 (dolphin) & armadolphin & Coordinating & $\begin{array}{l}\text { A hybrid of a dolphin and an } \\
\text { armadillo }\end{array}$ \\
\hline Word 1 (rhododendron) & rhododendelion & Right-headed & $\begin{array}{l}\text { A dandelion that grows in } \\
\text { rhododendron-like clusters }\end{array}$ \\
\hline Word 2 (dandelion) & rhododandelion & Coordinating & $\begin{array}{l}\text { A hybrid of a dandelion and a } \\
\text { rhododendron }\end{array}$ \\
\hline
\end{tabular}

\section{References}

Ahn, Suzy (2013). Faithfulness conflict in Korean blends. University of Pennsylvania Working Papers in Linguistics 20:1, $1-10$.

Alderete, John (1995). Faithfulness to prosodic heads. Ms., University of Massachusetts, Amherst .

Alderete, John (1999). Morphologically governed accent in Optimality Theory. Ph.D. thesis, University of Massachusetts, Amherst.

Arndt-Lappe, Sabine \& Ingo Plag (2013). The role of prosodic structure in the formation of English blends. English Language and Linguistics 17:3, 537-563.

Bat-El, Outi (1996). Selecting the best of the worst: the grammar of Hebrew blends. Phonology 13, 283-328.

Bat-El, Outi (2006). Blend. Brown, Keith (ed.), The Encyclopedia of Language and Linguistics, Elsevier, Oxford, England, vol. 2, 66-70, 2nd edn.

Bat-El, Outi \& Evan-Gary Cohen (2012). Stress in English blends: a constraint-based approach. Renner, Vincent, François Maniez \& Pierre J. L. Arnaud (eds.), Cross-disciplinary perspectives on lexical blending, Mouton de Gruyter, Berlin.

Beckman, Jill (1998). Positional faithfulness. Ph.D. thesis, University of Massachusetts, Amherst.

Benua, Laura (1997). Transderivational identity: phonological relations between words. Ph.D. thesis, University of Massachusetts, Amherst, Mass.

Berent, Iris, Tracy Lennertz, Jongho Jun, Miguel A. Moreno \& Paul Smolensky (2008). Language universals in human brains. Proceedings of the National Academy of Sciences, U.S.A. 105:14, 5321-5325.

Broselow, Ellen (2004). Unmarked structures and emergent rankings in second-language phonology. International Journal of Bilingualism 8:1, 51-65.

Carnegie Mellon Speech Group (2007). Carnegie Mellon pronouncing dictionary, Version 0.7a. Electronic resource.

Casali, Roderick (1996). Resolving hiatus. Ph.D. thesis, University of California, Los Angeles.

Davidson, Lisa, Peter W. Jusczyk \& Paul Smolensky (2004). The initial and final states: theoretical implications and experimental explorations of Richness of the Base. Kager, René, Joe Pater \& Wim Zonneveld (eds.), Constraints in phonological acquisition, Cambridge University Press, Cambridge, England, chap. 10, 321-368.

Gouskova, Maria (2003). Deriving economy: syncope in Optimality Theory. Ph.D. thesis, University of Massachusetts. 
Gries, Stephan Th. (2004a). Isn't that fantabulous? how similarity motivates intentional morphological blends in English. Acard, Michel \& Suzanne Kemmer (eds.), Language, Culture, and Mind, CSLI Publications, Stanford, California, chap. 28, 415-428.

Gries, Stefan Th. (2004b). Shouldn't it be breakfunch? a quantitative analysis of blend structure in English. Linguistics 42:3, 639-667.

Gries, Stefan Th. (2004c). Some characteristics of English morphological blends. Andronis, Mary A., Erin Debenport, Anne Pycha \& Keiko Yoshimura (eds.), Papers from the 38th Regional Meeting of the Chicago Linguistics Society, Vol. II: the panels, Chicago Linguistics Society, Chicago, 201-216.

Gries, Stefan Th. (2012). Quantitative corpus data on blend formation: psycho- and cognitive-linguistic perspectives. Renner, Vincent, François Maniez \& Pierre J. L. Arnaud (eds.), Cross-disciplinary perspectives on lexical blending, Mouton de Gruyter, Berlin, 145-167.

Hyman, Larry M. (2006). Word-prosodic typology. Phonology 23:2, 225-257.

Jaber, Aziz S. (2011). High vowel syncope in Jordanian Arabic: a positional faithfulness treatment. PhD qualifying paper, Department of Linguistics, University of North Carolina, Chapel Hill.

Kaunisto, M. (2000). Relations and proportions in the formation of blend words. Paper presented at the Fourth Conference of the International Quantitative Linguistics Organization (QUALICO), Prague.

Kelly, Michael H. (1998). To "brunch" or to "brench": some aspects of blend structure. Linguistics 36:3, 579-590.

Kubozono, Haruo (1989). The mora and syllable structure in Japanese: evidence from speech errors. Language and Speech 32:3, 249-278.

Kubozono, Haruo (1990). Phonological constraints on blending in english as a case for phonology-morphology interface. Yearbook of Morphology 3:1, 1-20.

Lombardi, Linda (1999). Positional faithfulness and voicing assimilation in optimality theory. Natural Language \& Linguistic Theory 17:2, 267-302.

McCarthy, John J. \& Alan M. Prince (1995). Faithfulness and reduplicative identity. Beckman, Jill N., Laura Walsh Dickey \& Suzanne Urbanczyk (eds.), Papers in Optimality Theory, no. 18 in University of Massachusetts Occasional Papers, Graduate Linguistic Students' Association, Amherst, Mass., 249-384.

Merriam-Webster Dictionary (2003). Merriam-webster, incorporated. Online version available at: www. mw. com.

Moreton, Elliott, Gary Feng \& Jennifer L. Smith (2008). Syllabification, sonority, and perception: new evidence from a language game. Edwards, R. L., P. J. Midtlyng, C. L. Sprague \& K. G. Stensrud (eds.), Papers from the 41 st Regional Meeting of the Chicago Linguistic Society, 341-355.

Oxford English Dictionary (2013). Oed online. Oxford University Press. http://www. oed. com.

Piñeros, Carlos E. (2004). The creation of portmanteaus in the extragrammatical morphology of Spanish. Probus 16:2, 203-240.

Plag, Ingo (2006). The variability of compound stress in english: structural, semantic and analogical factors. English Language and Linguistics 10:1, 143-172.

Prince, Alan \& Paul Smolensky (1993). Optimality Theory: constraint interaction in generative grammar. Department of Linguistics, Rutgers University.

Revithiadou, Anthi (1999). Headmost accent wins: head dominance and ideal prosodic form in lexical accent systems. Ph.D. thesis, University of Leiden.

Roon, Kevin (2006). Stress in Russian compound nouns: head dominance or anti-faithfulness? Lavine, James E., Steven Franks, Mila Tasseva-Kurktchieva \& Hana Filip (eds.), Proceedings of FASL (Formal Approaches to Slavic Linguistics) 14, Michigan Slavic Publications, 319-330.

Shaw, Katherine E. (2013). Head faithfulness in lexical blends: a positional approach to blend formation. Master's thesis, University of North Carolina, Chapel Hill.

Smith, Jennifer L. (2001). Lexical category and phonological contrast. Kirchner, R., J. Pater \& W. Wikely (eds.), PETL 6: Proceedings of the Workshop on the Lexicon in Phonetics and Phonology, University of Alberta, Edmonton, Alberta, 61-72.

Smith, Jennifer L. (2002). Phonological augmentation in prominent positions. Ph.D. thesis, University of Massachusetts, Amherst.

Smith, Jennifer L. (2004). Making constraints positional: towards a compositional model of con. Lingua 114:2, 14331464.

Smith, Jennifer L. (2011). Category-specific effects. van Oostendorp, Marc, Colin Ewen, Beth Hume \& Keren Rice (eds.), The Blackwell Companion to Phonology, Wiley-Blackwell, Malden, Mass., 2439-2463.

Thurner, D. (1993). Portmanteau dictionary: blend words in the English language, including trademarks and brand names. McFarland and Company, Jefferson, North Carolina.

Trommer, Jochen \& Eva Zimmermann (2010). Portmanteaus as generalized templates. Hanout from the 14th International Morphology Meeting, Budapest.

Zoll, Cheryl (1998). Positional asymmetries and licensing. MS, Rutgers Optimality Archive. 